\title{
Characteristics of Foreign Direct Investment into Agriculture in Ghana
}

\author{
Justice G. Djokoto \\ Department of Agribusiness, Central Business School, \\ Central University College, Accra, Greater Accra Region, Ghana. \\ Email:dgameli2002@gmail.com
}

\begin{abstract}
The paper investigated the characteristics of foreign direct investment(FDI) to Ghana's agriculture by examining the flow of funds, projects, employment and possible pre-independence legacies in FDI inflows from Ghana's former partners in colonial relationships and the slave trade. Using moving averages, percentages, cross tabulations and chi-squares tests, to data from 1994-2010, the following conclusions were drawn; a) FDI flows, measured by estimated cost of projects remained stable and low for most part of 1994-2010. However, huge jumps were witnessed after 2008, coinciding with Ghana's second time of successful and peaceful transfer of political power to another government; b) Clustering of agricultural projects in Greater Accra Region, c) a strong attraction of large FDI firms for the crops subsector; d) $75 \%$ of the FDI projects are SMEs; e) Among European countries, Ghana's former slave and colonial masters, Britain, Netherlands and Denmark contribute most FDI projects to Ghana's agriculture. Volta Region has strong attraction for projects from Germany. Strategies need to be designed to attract projects beyond Greater Accra, where poverty reduction may be better felt.
\end{abstract}

Key words: FDI; Agriculture; Employment; Distribution; Projects.

\section{Introduction}

\subsection{Background}

The agriculture sector plays a distinctive role in the development of any economy. It is the only source of food, which is essential in both developed and developing countries, contributes to the national income, and provides employment. These roles are even more pronounced in developing economies where the largest proportion of the population lives in rural areas and depends heavily, directly or indirectly on the sector (World Bank, 2008; Pg 3).

Additionally, with the sector being a vital source of employment with over 65 percent of the developing countries' labour force depending on agriculture, it is not surprising that agricultural development is fundamental in any poverty alleviation policy. Specifically for Ghana, agriculture employs more than $60 \%$ of the labour force and is predominantly rural. It also contributes significantly to gross domestic product (GDP) and foreign exchange earnings. For example, in 2006 the sector contributed $39.9 \%$ to GDP, and $41.1 \%$ of foreign exchange was derived from traditional and nontraditional crops (ISSER, 2007).
The major staple crops produced in Ghana include cereals (mainly rice and maize) and starchy staples such as yam, cassava and plantain. Crop production in Ghana is for three main reasons: food production for consumption, raw materials for industry and production for export. Animal production at the household level comprises poultry and small ruminants. Commercial production of animals is mainly in poultry. Thus, among the various sectors of the Ghanaian economy agriculture is expected to lead economic growth in much of the country.

Real GDP has increased more than 4 percent per year since 1980 and more than 5 percent per year since 2001. Growth and development in developing countries is dependent on agricultural development (World Bank, 2008). Moreover, agriculture is an important source of investment opportunities for both the private and public sectors and provides raw materials to industries in urban and rural areas (Suleman and Na'iya, 2009). Therefore, local and foreign direct investments (FDI) in the Agricultural sector, defined to include crop, livestock fisheries and forestry (excluding agro-processing and input supply) would be a welcome phenomenon. FDI comprise international capital flows by which a firm in one country creates or expands a subsidiary in another 
country. FDI refers to an investment made to acquire lasting interest in an enterprise operating outside of the economy of the investor (UNTAD, 2002). FDI can also be conceived as an investment involving a long-term relationship and reflecting a lasting interest and control of a resident entity (Rotjanapan, 2005). FDI thus implies that the investor has significant degree, partial or full control or influence on the management of the enterprise resident in the other economy. According to Krugman and Obstfeld (2009), the most distinctive feature of FDI is that it encompasses transfer of resources and acquisition of control. Consequently, UNCTAD (2002) delineates components of FDI as equity capital, reinvested earnings, and other capital.

\subsection{Literature}

Inward FDI is important to host countries for many reasons (Frimpong and Oteng-Abayie, 2008); that, the foreign capital inflow augment the supply of funds for investment thus promoting capital formation in the host country. FDI inflow can stimulate local investment by increasing domestic investment through links in the production chain when foreign firms buy locally made inputs or when foreign firms supply intermediate inputs to local firms. Furthermore, inward FDI can increase the host country's export capacity causing the developing country to increase its foreign exchange earnings. New job opportunities and enhancement of technology transfer, and boost of overall economic growth in host countries are definitely associated with inward FDI (Blomström and Kokko, 2003; Klein, Aaron, and Hadjimichael, 2003; Borenzstein, De Gregorio, and Lee, 1998). FDI works as a means of integrating developing countries into the global market place and increasing the capital available for investment, thus leading to increased economic growth needed to reduce poverty and raise living standards (Rutihinda, 2007; Dupasquier and Osakwe, 2005; Dollar and Kraay, 2000;). Productive employment generated from FDIs is a conduit to poverty reduction (Tambunan, 2004). Countries have benefited from FDIs. US FDI flows to Canada in 1987 stood at a little above US\$ $2000 \mathrm{~m}$ (Furtan and Holzman, 2004). This peaked at over $5000 \mathrm{~m}$ in 2000. This was consistently above the level of US's FDI to agriculture in Mexico, however, the flow into Mexico grew faster.

FDI in Chinese agricultural sector can be analysed in three phases. During the first phase (1980 to 1988), the amount of foreign capital was very low and the aggregate amount only reached 1 billion dollars (Li and Wahl, 2004). In the second period from 1989, the amount of foreign capital greatly increased. During the 1990s, FDI increased at an average rate of 66.1 percent, comprising three-fourths of the actual capital inflow. The third phase (2002-2004) was characterised by a new development for FDI in the agricultural sector.

With respect to Ghana, Tsikata, Asante and Gyasi (2000) also characterised total FDI flows to Ghana since 1983 into three phases namely; the period 1983-88, 1989-92 and 1993-96. The first period witnessed sluggish inflows, averaging about \$4 million per annum, and the highest and lowest inflows during the period being $\$ 6$ million in 1985 and \$2 million in 1984 respectively. The second, 1989-92 recorded moderate inflows averaging about $\$ 18$ million per annum the highest and lowest being \$22 million in 1992 and $\$ 14.8$ million in 1990 respectively. Thirdly, 1993-96 was a period of significant, but oscillatory inflows, which peaked in 1994 at \$233 million, but fell by more than $50 \%$ the following year to $\$ 107$ million.

A three-way nexus of economic growth, investment and political stability, emerged after the coup d'etat of 1972 (Tsikata et al, 2000). In that year, a growth rate of $2.3 \%$ was recorded, accompanied by a more than $60 \%$ drop in FDI (from $\$ 30.6$ million in 1971 to $\$ 11.5$ million in 1972). In 1979 when Rawlings took power and was perceived as anti-business, growth fell to as low as $-3.2 \%$; there was also an outflow of $\$ 2.8$ million of FDI. The state of the economy worsened further during his second term, from a negative growth rate of $3.5 \%$ in 1981 to $6.9 \%$ in 1982. However, inflow of FDI remained constant at $\$ 16.3$ million. Again, Ghana experienced a negative growth when a parliamentary democracy replaced the military junta in 1992 . The rate of growth of $5.3 \%$ in 1991 fell to $3.9 \%$ in 1992 . This has been previously attributed to deficit financing undertaken to finance the democratic process. The FDI flow however, increased from \$20million in 1991 to $\$ 22.5$ million in 1992.

Jansik (2009) has noted that in Central and Eastern Europe (CEE), food firms have tended to cluster around capital cities and surrounding areas. This confirms Ghana's experience with FDI. The factors that have attracted FDI to locations have been relatively high density of consumers' locations. On the contrary, nearness to agricultural raw materials did not positively influence location of foodprocessing firms. Again, in the case of location around capital cities, the contribution of those cities to 
agricultural and food processing output was not encouraging. Clearly, economies of scale and cost savings are key attractions for food processing FDIs in CEE. In China, FDIs to agriculture have been concentrated in the coastal areas, to the detriment of Central and Western areas (Li and Wahl, 2004). Quan (2006) confirmed the China story. In Ghana, the case is not different. Greater Accra, an eastern coastal region, attracts the most of all FDIs (Abdulai, 2005).

\subsection{Problem statement}

The growth in agriculture is dependent on investments at all levels from investments in Agriculture inputs, infrastructure and across the value chain (Suleman and Na'iya, 2009). However, Ghana does not have the resources to stimulate and develop the agriculture sector. Hence, FDI in the agriculture sector is critical, and an important tool in the fight against poverty. Despite this, the sector does not receive due prominence from both the governments of developing countries and their development partners. For instance, only 4 percent of development assistance goes to the sector in developing countries. In Sub-Saharan Africa, a region where over 60 percent of the population lives in the rural areas, and the level of dependence on agriculture for overall economic growth is very high, the sector is seriously neglected with public sector spending on agriculture accounting for only 4 percent of total government spending (World Bank, 2009).

To this end, what is the real picture of FDI flows to Ghana's agriculture? Specifically, which geographical locations attract agriculture FDI projects? What is the level of employment generated? Which subsectors of agriculture in Ghana receives FDI projects? Then, recalling the pre-independence relation between Ghana on one hand and the Danes, the Dutch, Germans, and the British during the slave trade and subsequent colonisation on the other hand, are there any attractions from these countries for Ghana and specifically, Germany and the Danes for Volta Region?

\subsection{Objectives}

In response to the questions posed above, the paper seeks to describe the flow of FDI into agriculture in Ghana, identify which regions that attract FDI projects, and determine the employment benefits to Ghana as well as the regional distribution of employment generated. Finally, the possible attraction of Volta Region and Ghana as a whole to the former colonial masters and slave trade partners will be assessed.

\subsection{Organisation}

The rest of the paper is organised into three sections. The next section describes the data and methods employed. The results of the analysis are presented and discussed in section three. Then comes the conclusion and recommendation in the fourth section.

\section{Methodology}

The paper employed only secondary data which were obtained from Ghana Investment Promotion Centre (GIPC). These covered September of 1994 to December, 2010. A three-year moving average by the help of Microsoft Excel 2010 was computed to show the trend of agriculture FDI over time. Number of projects, employment and their regional distributions as well as sources analyses for Ghana and specifics for Volta region were achieved using cross tabulations in SPSS. Chi-square and likelihood ratios were computed to test for association among variables. Results are presented using appropriate tables and charts.

\section{Results and discussion}

Annual FDI inward flows to agriculture from 1994-2010 based on estimated costs of projects is presented in Figure 1. The FDI inflows were generally below \$50m between 1994 and 2007, except for 1997. Leaps were experienced in 2008-2010. The highest jump was in 2010 , an addition of about $\$ 250 \mathrm{~m}$, registering $\$ 344 \mathrm{~m}$.

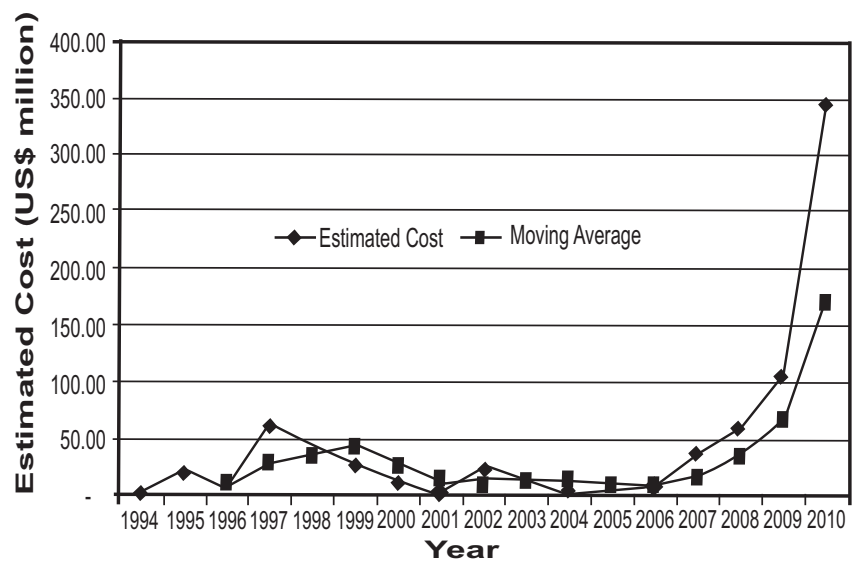

Fig. 1: Annual estimated cost of agriculture FDI projects, Ghana 1994 2010 
The moving average line shifted the peak of 1997 to 1999 , but with a value of US $\$ 42 \mathrm{~m}$ lower than the US $\$ 60 \mathrm{~m}$. Between 2002 and 2010, the moving averages were below the actual flow levels. Breaking the flows of US $\$ 744.59 \mathrm{~m}$ among subsectors of Agriculture (Figure 2), forestry attracted the highest of US $\$ 300 \mathrm{~m}$ followed by combined subsectors; US $\$ 219 \mathrm{~m}$ and crops; US $\$ 170 \mathrm{~m}$. The least attractive subsector is livestock, US\$15.24 over the period 19942010. In respect of origin of FDIs, Central America contributed almost half of the total estimated cost of projects (Figure 3). Europe came second with US $\$ 167.01 \mathrm{~m}$. The least is Australia with US $\$ 0.24 \mathrm{~m}$. The surge of Asia, particularly China and India in FDIs is not that strong in agriculture in Ghana.

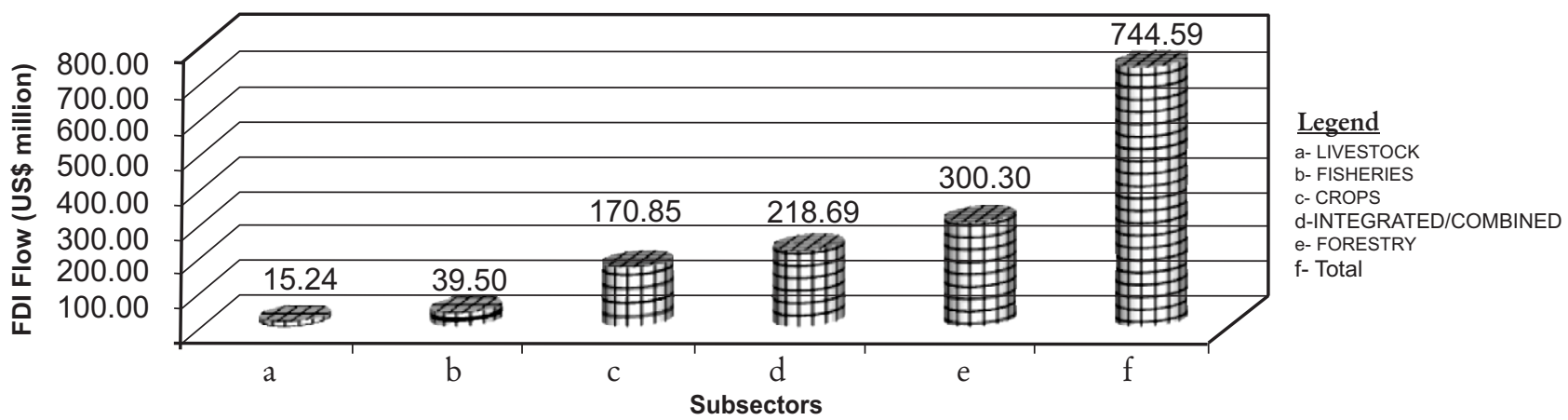

Fig. 2: Flow of agriculture FDI subsectors, (1994-2010)

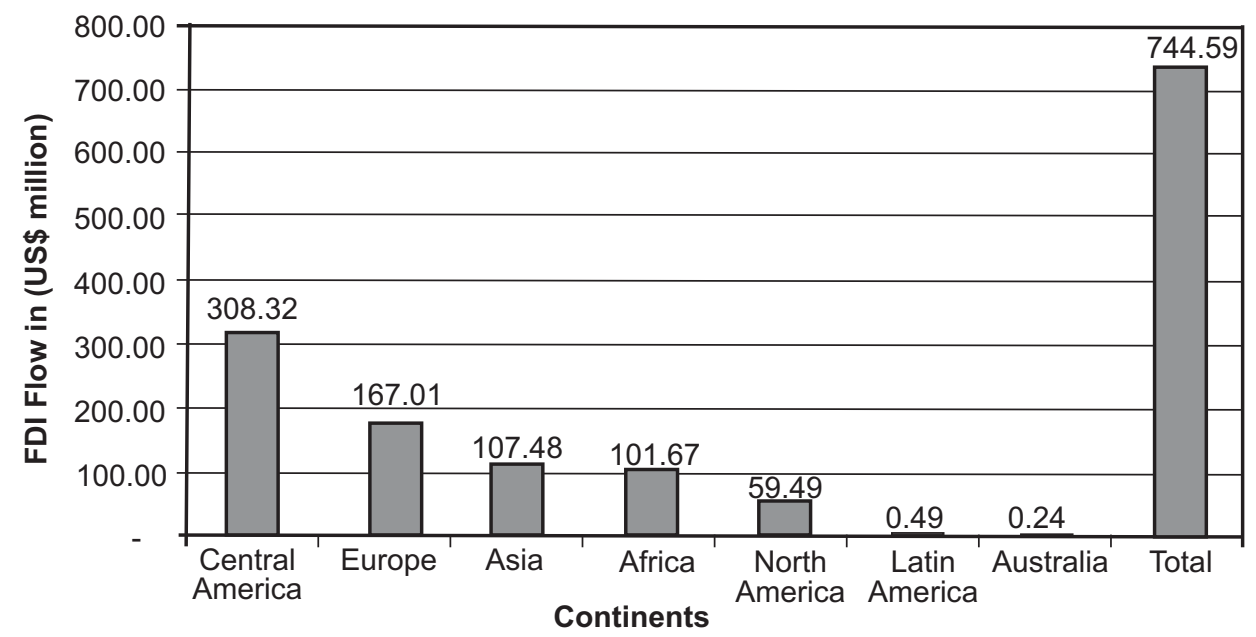

Fig. 3: Flow of agriculture FDI from continents, (1994-2010)

In Figure 4, the number of flows of registered FDI projects in Ghana is presented. The levels show gyrated movements. With as low as two projects in 1994, to a high of 18 in 1998 and a drop to 7 in 2000.
The subsequent oscillatory movements peaked at 16 in 2008, with 11 projects terminating the line in 2010. Clearly, the peak of 18 projects registered in 1998 is yet to be equalled after more than a decade.

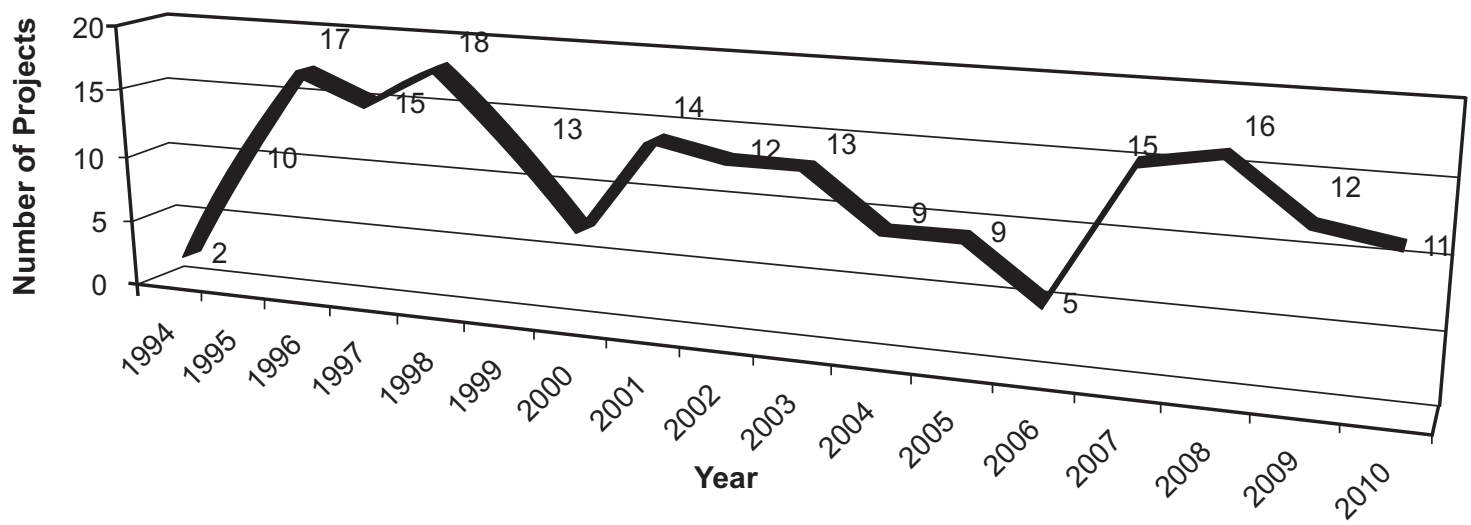

Fig. 4: Registered annual FDI agricultural project (1994-2010) 
Within the country, there was significant disparity in the regional distribution of projects (Figure 5).

\begin{tabular}{ll}
\multicolumn{2}{l}{ Legend } \\
GR & - Greater Accra Region \\
ER & - Eastern Region \\
VR & - Volta Region \\
CR & - Central Region \\
AR & - Ashanti Region \\
NR & - Northern Region \\
WR & - Western Region \\
BR & - Brong-Ahafo Region \\
UER & - Upper East Region \\
UWR & - Upper West Region
\end{tabular}

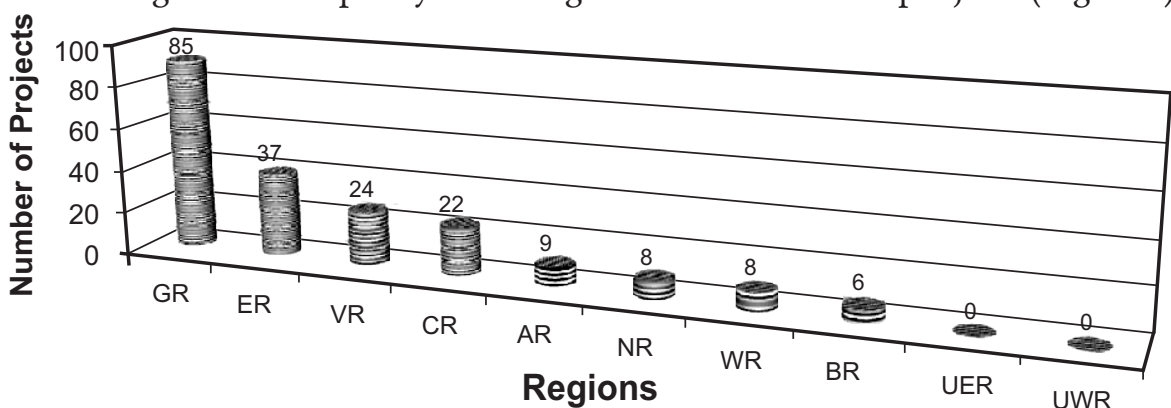

Fig. 5: Regional distribution of registered agricultural FDI project (1994-2010)

Greater Accra Region attracted 85 projects, more than twice the level of the next most attractive region Eastern (37). This clustering of projects within the region that hosts the capital city is not peculiar to agriculture in Ghana (Abdulai, 2005). So it is in Central and Eastern European Countries (Jansik,2009). In the Ghanaian case, it might be attributed to the nearness to the port of Tema, as quite a number of these firms are export oriented. Volta Region recorded 24, Central 22 and Ashanti 9. Western Region and Brong-Ahafo Region recorded 8 each.

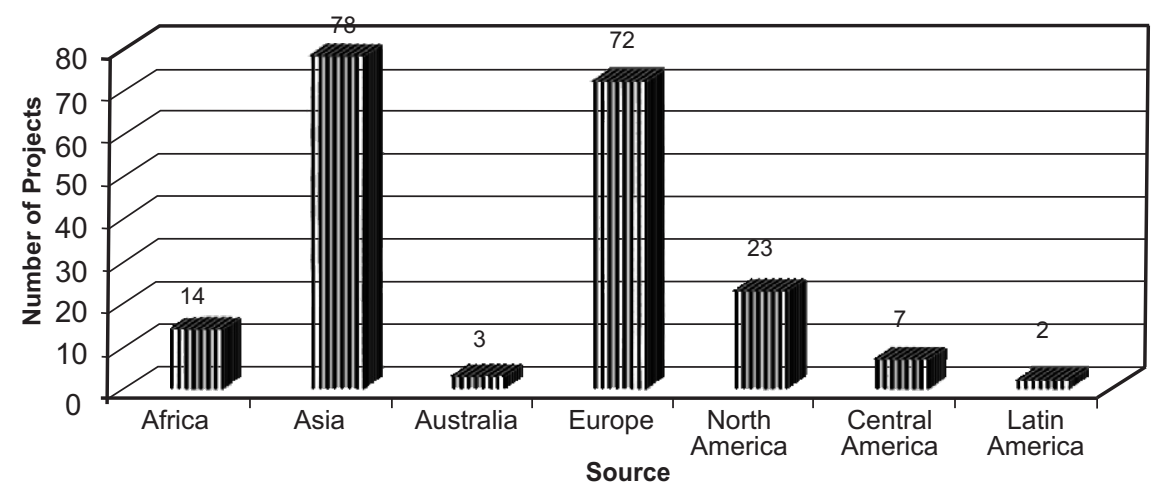

Fig. 6: Distribution of registered agricultural FDI project by source (1994-2010)

As many as 78 of the projects originated from Asia, followed by 72 from Europe and 2 from Latin America. Though Central America showed the highest estimated cost of projects over the 17-year period (figure 3), this did not reflect in the number of projects. The most likely situation is that the few projects registered consisted of huge estimated costs. The aggregation of origin of FDIs may hide individual
The trend suggests that, the farther a region is from the national capital, the fewer the projects it attracts. The null registration of projects for the two upper regions is particularly worrying from the rural development perspective. Though it is furthest from the Accra, the levels of poverty are higher. Thus, it would be desirable to attract projects to the regions to create employment. Indeed, the poverty reduction effect noted by Abdulai (2005) remains unaddressed. The origins of registered projects are shown in figure 6. 
On the other hand, Brong-Ahafo Region with six projects over the period attracted the most estimated cost of US $\$ 301.27 \mathrm{~m}$. Crops subsector, registered the highest number of projects, 93 (figure 8).

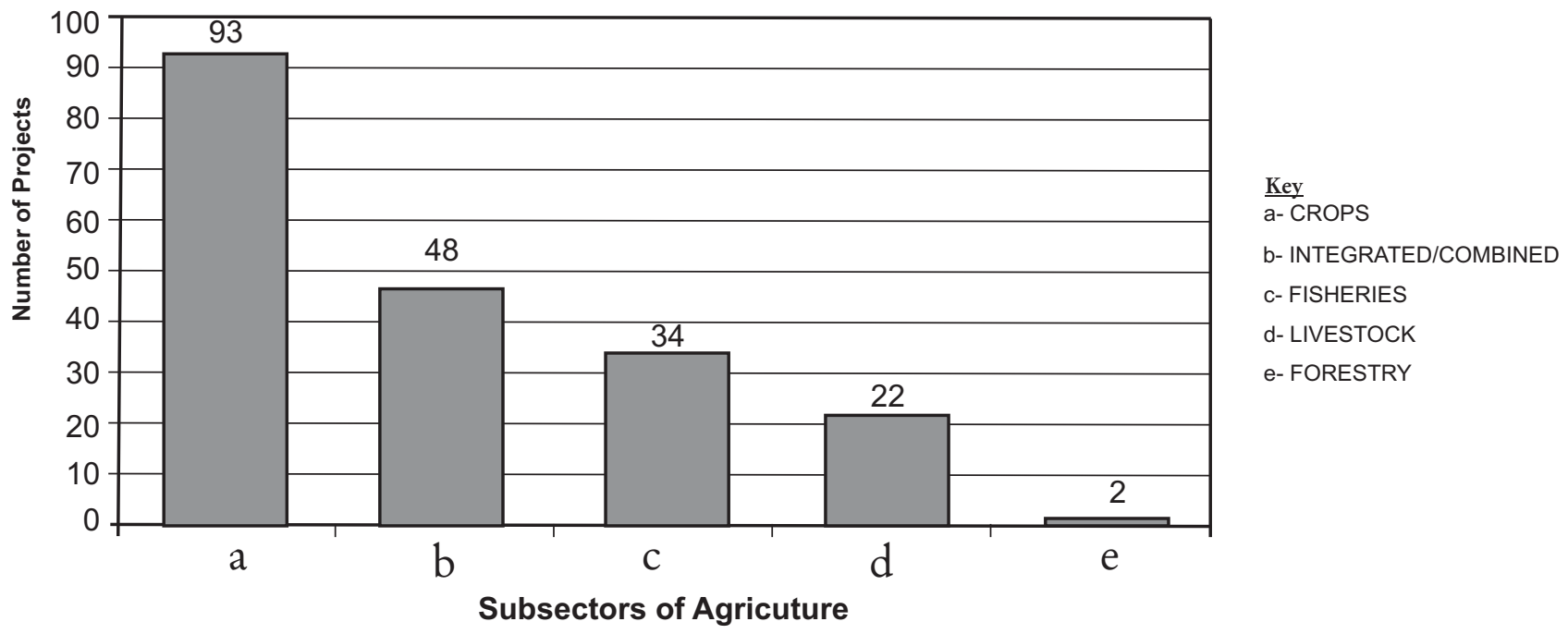

Fig. 8: Distribution of registered agricultural FDI projects in subsectors (1994-2010)

Forestry is the least with 2 projects. One of the desirable effects of FDI is employment (Fimpong and Oteng-Abayie, 2008). Employment generation of FDI to agriculture was firstly investigated. It was observed that employment was indeed generated by FDI projects in agriculture (figure 9). This ranged from a low of 232 in 1994 to a high of 3073 in 2009.

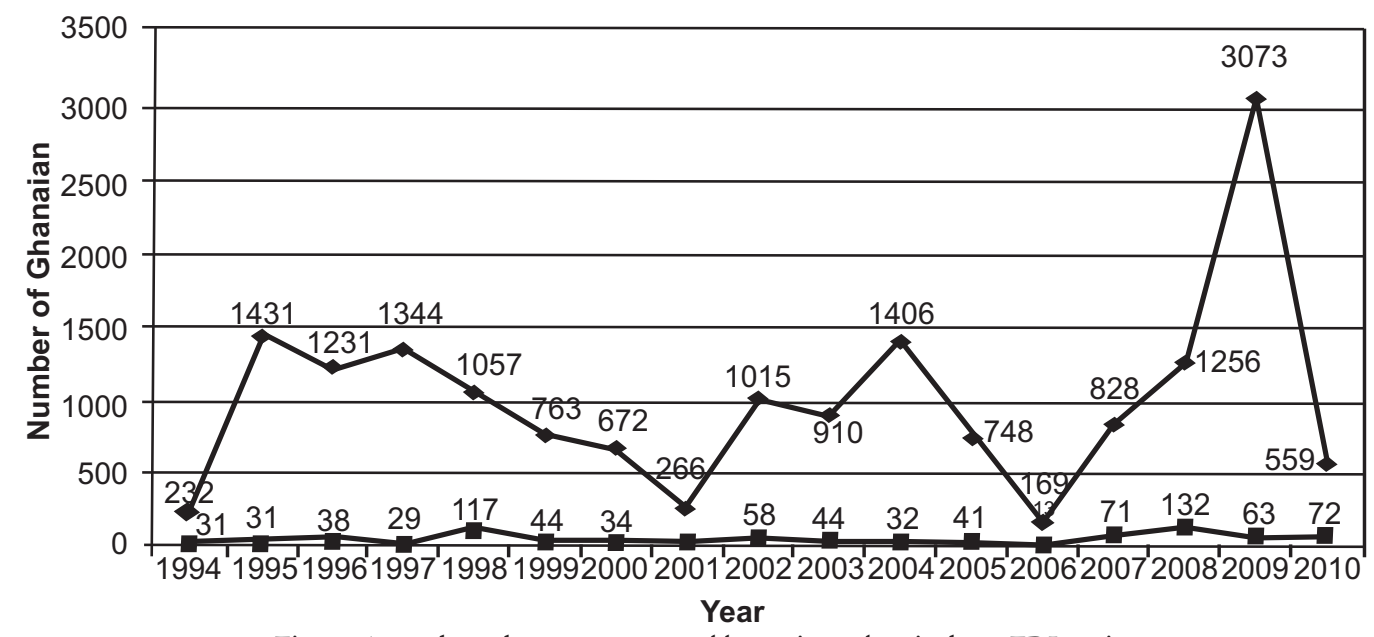

Fig. 9: Annual employment generated by registered agriculture FDI projects

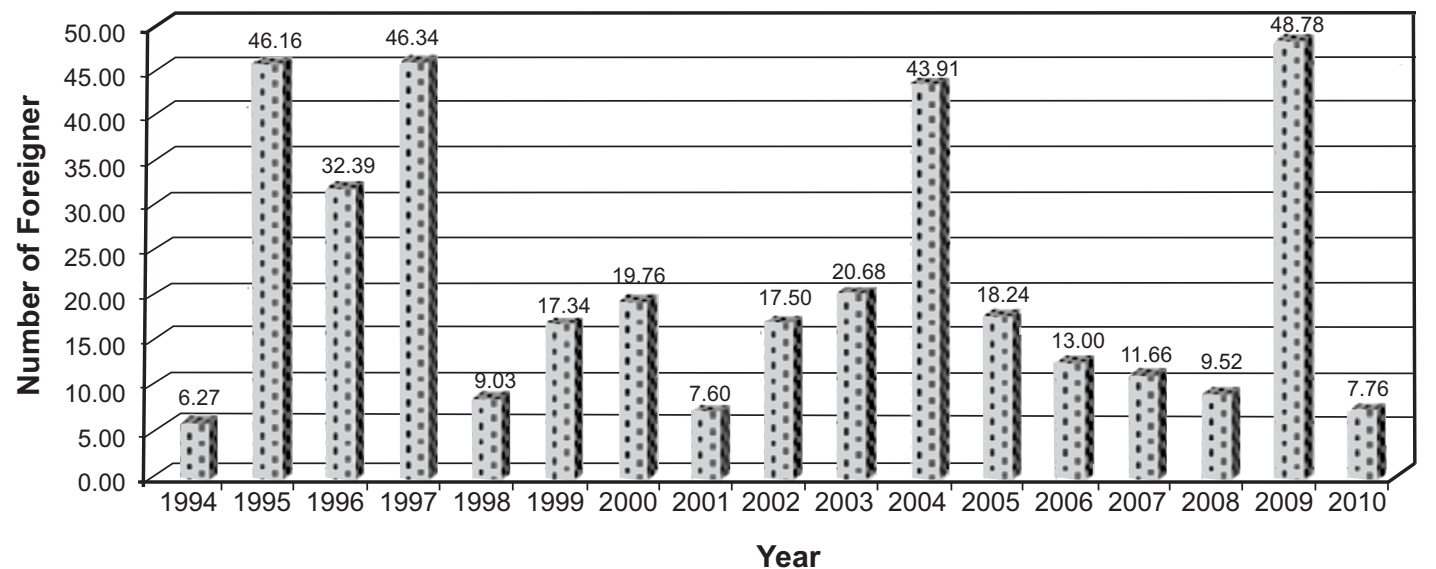

Fig. 10: Number of Ghanaian per foreign employee for registered agricultural FDI projects 
The levels however, fluctuated between 2008 and 2010. The number of employment avenues which were 1,296 in 2008 , rose to 3,073 in 2009 but declined to 569 in 2010.

The number of foreign employees however remained generally flat over the 17-year period. Secondly, figure 9 was recomposed into figure 10, to show the ratio between Ghanaian employees and foreign employees. The highest rate was 48.78 per foreign employee in 2009. Within the 17-years, the rate exceeded 25 per foreign employee for only five years.

Thirdly, the size of the FDI projects, defined by number of employees, was investigated. Following a classification of less than 6 employees as micro, between 6 and 20 as small, 30-99 employees as medium, and more than 100 as large, about 40\% (78) of the 199 projects were medium scale (figure 11).

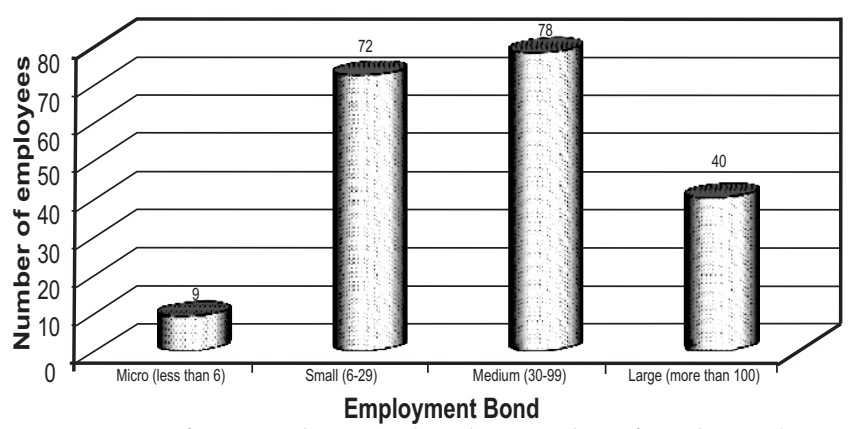

Fig. 11: Size of registered projects based on number of employees (19942010)

With 36\% (72) small scale and 20\% (40) large scale. Indeed, $75 \%$ (150) of registered projects were small and medium scale firms. One would have expected more large businesses. This is in line with China where, Quan (2006) laments that, FDI projects into agriculture are small scale. From the internationalisation perspective, foreign firms may be starting as SMEs and to remain as such or grow into large-scale organisations.

Lastly, association between size of business and subsectors of agriculture was examined (Table 1). By the aid of cross tabulation, crops subsector attracted larger firms followed by fisheries and livestock. The Pearson Chi-Square Tests (PCS) statistics and the Likelihood Ratio (LR) were computed for the cross tabulation. The PCS value of 28.399 was significant at $0.5 \%$ and the LR value of 25.022 was significant at $1.5 \%$. Adopting a $10 \%$ level for social sciences, clearly, there was a significant association between firm size and subsector of agriculture. Stated formally, larger FDI projects tended to be registered for crops and the least for livestock.
Table 1

Association between size of business and subsector

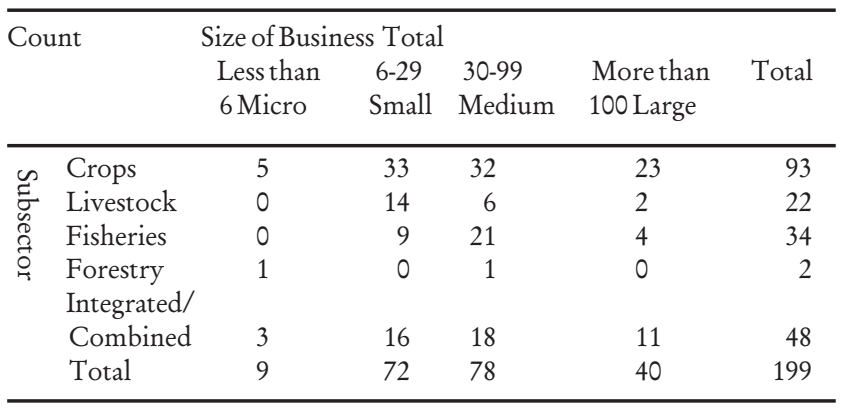

Chi-Square Tests

\begin{tabular}{lrrc}
\hline & Value & df & Asymp. Sig. (2-sided) \\
\hline Pearson Chi-Square & 28.399 & 12 & .005 \\
Likelihood Ratio & 25.022 & 12 & .015 \\
Linear-by-Linear Association & .000 & 1 & .987 \\
N of Valid Cases & 199 & & \\
\hline
\end{tabular}

Turning to the last objective of the paper, flow of projects from Denmark, UK and Germany and Netherlands were investigated. Table 2 and figure 12 present the results.

Table 2

Distribution of agriculture FDI from Europe in volta region

\begin{tabular}{lrrrr}
\hline & VR & All Regions\% & $\begin{array}{l}\text { VR In All } \\
\text { Regions }\end{array}$ & \% In VR \\
\hline Belgium & 1 & 6 & 16.7 & 9.09 \\
Britain + & 2 & 15 & 13.3 & 18.18 \\
Denmark & 0 & 4 & 0.0 & - \\
France & 1 & 4 & 25.0 & 9.09 \\
Germany & 3 & 13 & 23.1 & 27.27 \\
Greece & 0 & 1 & 0.0 & - \\
Italy & 0 & 1 & 0.0 & - \\
Netherlands & 2 & 14 & 14.3 & 18.18 \\
Norway & 0 & 3 & 0.0 & - \\
Spain & 0 & 3 & 0.0 & - \\
Sweden & 1 & 1 & 100.0 & 9.09 \\
Switzerland & 1 & 6 & 16.7 & 9.09 \\
Total & 11 & 72 & 15.3 & 100.00 \\
& & & & \\
\hline
\end{tabular}




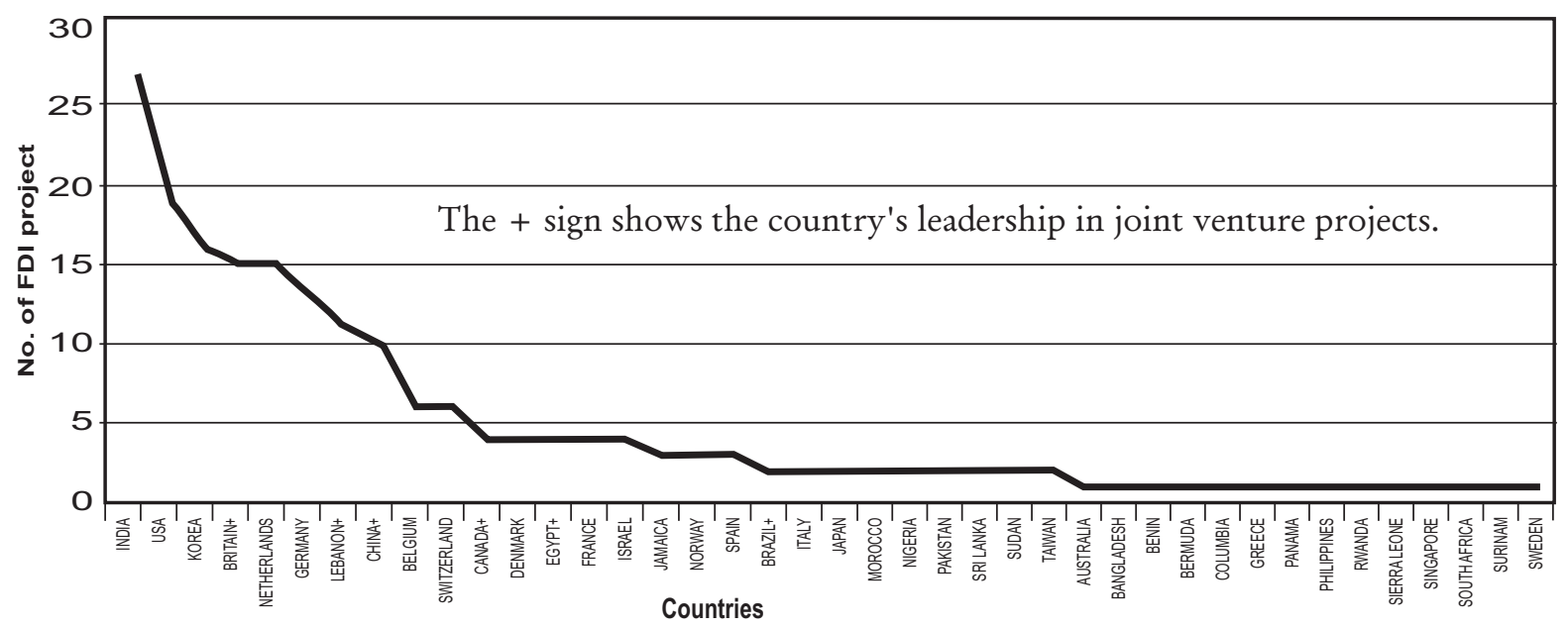

Fig. 12: Number of registered agriculture FDI projects by source country (1994-2010)

Column 2 of table 2 reveals that the top three projects from Europe into Ghana came from Britain (15), Netherlands (14), and Germany (13). Denmark registered 3 projects just below the 6 each by Belgium and Switzerland. These results points to projects attractions possibly due to old relationships. In the case of Volta region, which was under German rule until the British took over, 3 (27\%) out of $11(100 \%)$ projects in the region originated from Germany. Compared to all regions, the 3 project from Germany constituted $23 \%$ of all German projects in Ghana (column 4). Including all countries, Britain, Netherlands, and Germany were the top European countries to register projects in Ghana (figure 12).

\section{Conclusions}

FDI flows to Ghana's agriculture was generally stable, between 1994 and 2007. Sustained increases were observed after 2008, which period coincided with the second successful and peaceful change of government in Ghana. The results suggest that the current democratic dispensation should be continued and strengthened. Additionally, efforts need to be made to attract more FDIs to agriculture in Ghana. Spatial distribution of projects clustered around Greater Accra Region, a phenomenon noted by Abdulai (2005) for Ghanaian FDIs and in CEE countries in for food firms (Jansik, 2009). The two upper regions, where poverty is highest, did not register a single project over the 17 -year period.

A lot remains to be done in developing infrastructure and increasing accessibility to the two Upper regions. Attention could be paid to attracting firms that would target Burkina Faso, Northern Togo, and La Cote d'voire as markets. Additionally, policies that will encourage more people to reside in those regions will help in attracting firms that produce for the local market.

The subsector that attracts most projects is crops. Indeed, there is a strong association between size of firm and subsector. Larger firms tended to be registered in the crops subsector. Using number of employed Ghanaians in determining size of projects, SMEs dominate the projects constituting more than $75 \%$ of projects registered.

The attraction of crops subsector to FDIs signals the need to strengthen this sector to attract more funds and projects. However, fewer projects in livestock and fisheries point to gaps in these subsectors that must be addressed to attract investors. There may be a link between Ghana and its colonial masters. Among European countries, Britain, Netherlands, and Germany registered the most projects in Ghana respectively. Relationships with these countries must be strengthened. Volta Region, the only region ever colonised by Germany, registered the highest number of projects, among all European countries, and indeed, the highest compared to German projects registered in all of Ghana. One may hypothesis a link between German Business and their former colony.

This finding provides an impetus for managers of the region to design strategies that will foster closer ties with Germany. An investment tour by the leaders of the Region to Germany should be considered. 


\section{References}

Abdulai, I. ,(2005). Sectoral Analysis of Foreign Direct Investors in Ghana. Working Paper WP/BOG2005/15, Bank of Ghana, Accra.

Blomström ,M., and Kokko ,A., (2003). The Economics of Foreign Direct Investment Incentives, EIJS Working papers 168. Retrieved from http://www.hhs.se/eijs

Borenzstein, E., De Gregorio, J., and Lee, J.W., (1998). How does Foreign Direct Investment Affect Economic Growth? Journal of International Economics. Vol. 45, pp. 115-135.

Dollar, D., and Aart, K., (2000). Growth is Good for the Poor. Development Research Group. Washington, D.C.: World Bank. Retrieved from http://wwwwds.worldbank.org/

Dupasquier, C., and Patrick, N. O., (2005). Foreign Direct Investment in Africa: Performance, Challenges and Responsibilities. Africa Trade Policy Center (ATPC), Work in Progress No. 21. Retrieved from http://www.uneca.org/atpc/

Frimpong, J.M., and Oteng-Abayie, E.F. ,(2008). Bivariate Causality Analysis between FDI Inflows and Economic Growth in Ghana. International Research Journal of Finance and Economics Issue 15 (2008), Available at http://www.eurojournals.com/ finance.htm

Furtan, W.H., and Holzman, J.J., (2004). The Effect of FDI on Agriculture and Food Trade: An Empirical Analysis. Agriculture and Rural Working Paper Series. Working Paper No. 68.

Hung, H. T., (2006). Attracting FDI in Agriculture and Rural Development- Status and Solutions for Improvement Policy Advisory Briefing (PAB) No. 4. International Support Group, Ministry of Agriculture and Rural Development, Vietnam.

Institute of Statistical, Social and Economic Research (ISSER) (2007). The State of the Ghanaian Economy, Legon, Accra.

Jansik, C., (2009). Geographical Aspects of Food Industry FDI in the CEE Countries. EuroChoices Vol.8, Issue 1, pp 46-51.
Klein, M., Aaron, C., and Hadjimichael, B., (2003). Foreign Direct Investment and Poverty Reduction. World Bank, Retrieved from http://lcgbangladesh.org

Krugman, P., and Obstfeld, M. ,(2009). International Economics Theory and Policy,(8th ed.). Pearson Addison Wesley, USA.

Li, Q., and Wahl, T.I., (2004). Efficiency and Technological Progress in the Chinese Agriculture: the Role of Foreign Direct. Investment Selected paper presented at the American Agricultural Economics Association Annual Meetings, Denver, CO-August 14,2004

Rotjanapan, A., (2005). Topics in foreign investment, The University of Kansas.

Rutihinda, C., (2007). Impact of Globalization on Small and Medium Size firms in Tanzania. ABR and TLC Conference Proceedings, Hawaii, USA. Retrieved from http://www.cluteinstitute.com/Programs/Hawaii2007/Article\%20293.pdf

Suleman, A. , and Na'iya, I.I. ,(2009). Fostering IntraOIC FDI in the Agricultural Sector. Occasional Paper, No. 14.Economic Policy and Statistics Department, Islamic Development Bank, Saudi Arabia.

Tambulan, T., (2004). The Impact of Foreign Direct Investment on Poverty Reduction: A Survey of Literature and a Temporary Finding from Indonesia. Faculty of Economics, University of Trisakti, Indonesia. Retrieved from http://www.trisakti.ac.id/

Tsikata, G. K., Asante, Y., and Gyasi, E. M., (2000). Determinants of Foreign Direct Investment in Ghana. Overseas Development Institute. London (UK).

UNCTAD., (2002). Foreign Direct Investment Statistics.

World Bank Annual Report (2009). Global Economic Prospects; Commodities at the Crossroads. Washington DC.

Zhan-qi, Q., (2006). Discussion on Reasons of Less Drawing FDI for Our Agriculture and Corresponding Measures. Journal of Liaoning Institute of Science and Technology 2006/01. 